\title{
Effect of Initial Microstructure on Phase Precipitation and Mechanical Properties during Heat Treatment of TC21 Titanium Alloy
}

\author{
Liuru Wang1*, Xiangqian Song1, Yue Zhang2, Lian Zhou ${ }^{3}$ \\ ${ }^{1}$ School of Shipping and Mechatronic Engineering, Taizhou University, Taizhou, China \\ ${ }^{2}$ School of Intelligent Manufacture, Taizhou Institute of Sci. \& Tech., NJUST., Taizhou, China \\ ${ }^{3}$ Northwest Institute for Nonferrous Metal Research, Xi'an, China \\ Email: *wanglinru@126.com
}

How to cite this paper: Wang, L.R., Song, X.Q., Zhang, Y. and Zhou, L. (2020) Effect of Initial Microstructure on Phase Precipitation and Mechanical Properties during Heat Treatment of TC21 Titanium Alloy. Engineering, 12, 781-789.

https://doi.org/10.4236/eng.2020.1210055

Received: September 27, 2020

Accepted: October 25, 2020

Published: October 28, 2020

Copyright $\odot 2020$ by author(s) and Scientific Research Publishing Inc. This work is licensed under the Creative Commons Attribution International License (CC BY 4.0).

http://creativecommons.org/licenses/by/4.0/

\begin{abstract}
Phase precipitation and mechanical properties of TC21 titanium alloy with two different initial microstructures during heat treatment were determined. Result indicated that compared with coarse microstructure alloy, fine microstructure alloy developed finer microstructure, more unstable $\omega$ and $\alpha_{2}$ precipitates with much smaller size and lower volume fraction, and obtained better mechanical properties during heat treatment.
\end{abstract}

\section{Keywords}

TC21 Titanium Alloy, Fine Microstructure, Mechanical Properties, Phase Precipitation

\section{Introduction}

TC21 titanium alloy is widely used in aerospace applications due to its low density-strength ratio, high strength and high toughness [1] [2] [3]. However, it is usually considered to be among the most difficult to process due to its higher yield-tensile ratio and lower elastic modulus [4]. Previous researches on TC21 titanium alloy primarily highlighted the role of conventional hot working methods controlling mechanical properties of TC21 titanium alloy, especially strength and fracture toughness, by adjusting $\alpha$ grain morphology and content [1] [2] [3]. Therefore, it is necessary to develop a new processing technique to improve the formability of TC21 titanium alloy.

Grain refinement is well recognized as an effective approach to enhance the properties of titanium alloys [4] [5] [6] [7]. One factor affecting the level of grain 
refinement is the initial microstructure of titanium alloys. As a result of deformation-induced continuous dynamic recrystallization, the acicular or lamellar microstructure can be transformed into fine microstructure with increased strength, ductility and superplasticity [4] [5] [6] [8]. As we all know, the fine microstructure becomes instable during moderate and high temperature exposure. However, instable microstructure has a considerable effect on properties of titanium alloys. Besides, little attention was paid to the phase precipitation and mechanical properties of the fine microstructure alloys during heat treatment (high temperature exposure).

The objective of this work was to investigate the microstructure evolution and mechanical properties of TC21 titanium with fine and coarse microstructures during heat treatment.

\section{Materials and Procedures}

The material of this work was a $220 \mathrm{~mm}$-diameter hot-forged TC21 bar stock with an equiaxed $\alpha$ microstructure (a grain size of $\sim 6 \mu \mathrm{m}$ ). Its chemical compositions were (by wt\%) $6.3 \mathrm{Al}, 2.13 \mathrm{Sn}, 2.89 \mathrm{Mo}, 1.63 \mathrm{Cr}, 2.3 \mathrm{Zr}, 2.02 \mathrm{Nb}, 0.11 \mathrm{Si}$, and $82.62 \mathrm{Ti}$. The $\beta$ transus temperature of the material was approximately $940^{\circ} \mathrm{C}$. A section of the TC21 bar stock was rolled at $900^{\circ} \mathrm{C}$ to produce an equiaxed $\alpha$ microstructure with a grain size of $\sim 5 \mu \mathrm{m}$ (coarse microstructure) (Figure 1(a)). Another section of the TC21 bar stock was water quenched at $970^{\circ} \mathrm{C}$ to obtain an acicular $\alpha$ microstructure and then was rolled at $900^{\circ} \mathrm{C}$ to produce a fine microstructure with a grain size of $\sim 0.5 \mu \mathrm{m}$ (Figure $1(\mathrm{~b})$ ). The volume fractions of equiaxed $\alpha$ phases in the fine and coarse microstructures were both about $60 \%$. Both materials with the fine and coarse microstructures were heat-treated at $900^{\circ} \mathrm{C} / 1 \mathrm{~h}+550^{\circ} \mathrm{C} / 4 \mathrm{~h}$ in order to obtain excellent comprehensive properties.

The microstructures of materials were studied using a JMS-6460 scanning electron microscope (SEM) equipped with an OxFORD EDS system and a Hitachi HF 2000 field emission transmission electron microscope (FE-TEM). X-ray diffraction was used to determine the crystallographic texture of materials.

The tensile tests were conducted on cylindrical materials with a gauge diameter of $5 \mathrm{~mm}$ and length of $70 \mathrm{~mm}$ at room temperature. The fracture mechanics tests were performed on $40 \mathrm{~mm}$ wide and $20 \mathrm{~mm}$ thickness CT-materials, which were precracked in air at $\mathrm{R}=0.1$. To demonstrate the influence of initial microstructure on the crack growth behavior, additional CT-materials were selected to perform the same fracture mechanics, but the loading were removed before they broke. Their crack paths were observed using an Olympus optical microscope.

\section{Results}

\subsection{Microstructure and Precipitation}

SEM microstructures of TC21 titanium alloy with the coarse and the fine microstructures heat treated at $900^{\circ} \mathrm{C} / 1 \mathrm{~h}+550^{\circ} \mathrm{C} / 4 \mathrm{~h}$ were showed in Figure $2(\mathrm{a})$ and 

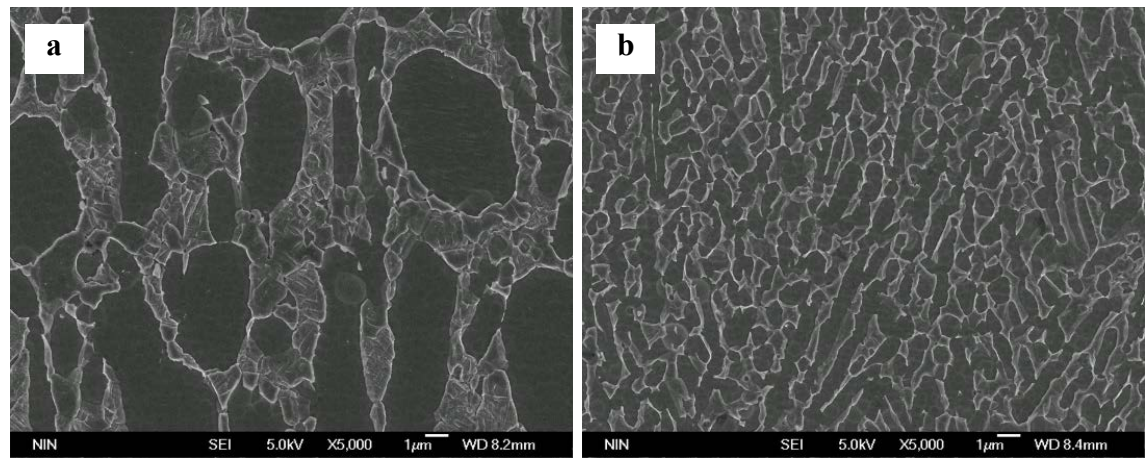

Figure 1. SEM micrographs of TC21 titanium alloys with (a) coarse and (b) fine microstructures.

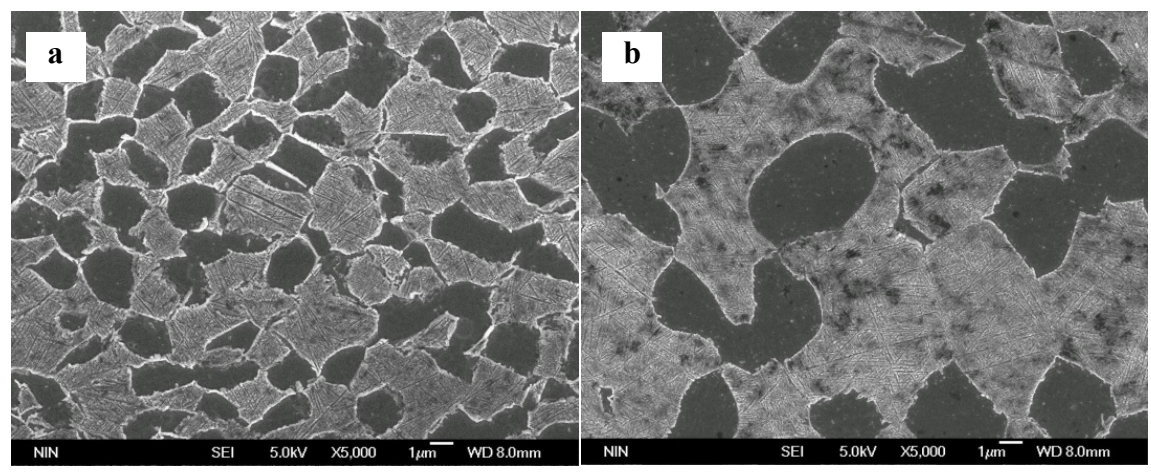

Figure 2. SEM micrographs of TC21 titanium alloys with (a) fine and (b) coarse microstructures heat-treated at $900^{\circ} \mathrm{C} / 1 \mathrm{~h}+550^{\circ} \mathrm{C} / 4 \mathrm{~h}$.

Figure 2(b), respectively. It was observed that the bimodal microstructure consists of equiaxed and lamellar $\alpha$-phase grains. The volume fractions of equiaxed $\alpha$-phase grains in the two materials were same (about 35\%). The measured sizes of $\alpha$ - and $\beta$-phase grains were $\sim 7$ and $\sim 12 \mu \mathrm{m}$ respectively in the coarse microstructure, while $\sim 3$ and $\sim 5 \mu \mathrm{m}$ respectively in the fine microstructure (Figure 2(b)).

Occurrence of $\omega$ precipitates in $\sim 10 \mathrm{~nm}$ scale in the two materials were clearly observed by TEM imaging, as shown in Figures 3(a)-(e). Dark field (DF) images of the two materials were shown in Figure 3(c) and Figure 3(f), respectively. The second $\alpha$ precipitates from the two materials exhibited a lamellar morphology. However, the thickness of the second $\alpha$ lamellae (sub-50 nm) in the coarse microstructure was finer than that in the fine microstructure (sub-200 nm). Moreover, the orientation relationships of the two materials between $\alpha$ and $\beta$ phases was $\left.\langle 111\rangle_{\beta} / /<11-20\right\rangle_{\alpha},\{110\}_{\beta} / /\{0001\}_{\alpha}$. The second $\alpha$ lamellae exhibited a Burgers orientation relationship with the surrounding $\beta$ matrix. Similar results were reported in previous studies [9].

$\omega$ reflections deviated from the three dimensional positions of $\omega$ phase were shown from Figure 3(a) and Figure 3(d). The deviation was normalized as $|\Delta|=$ $2 u /\left(k_{0} / 3\right)$ [10], where $k_{0}$ was the distance between $(-110)_{\beta}$ and $(1-1-2)_{\beta}$ reflections and $\mathrm{u}$ was the shift of diffuse scattering from the $k_{0} / 3$ position. Early studies 

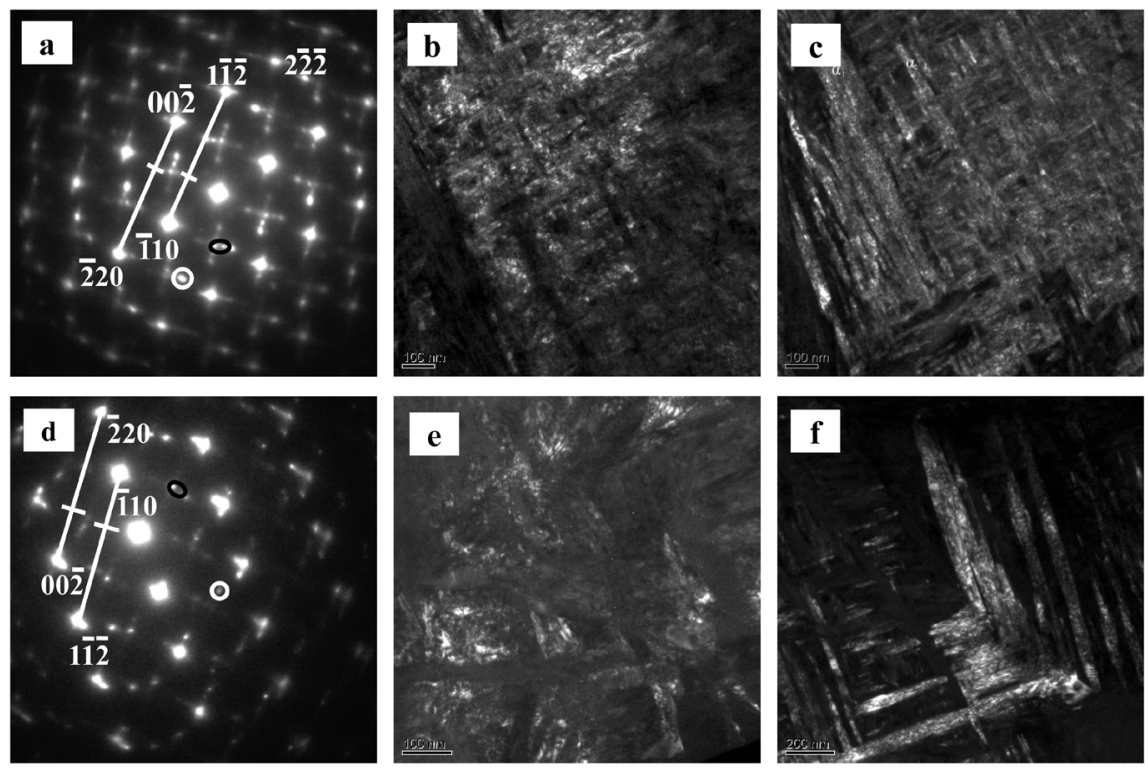

Figure 3. TEM images of TC21 titanium alloys with (a-c) coarse and (d-f) fine microstructures heat-treated at $900^{\circ} \mathrm{C} / 1 \mathrm{~h}+550^{\circ} \mathrm{C} / 4 \mathrm{~h} ;(\mathrm{a}, \mathrm{d})$ the SADPs of $[110]_{\beta}$ zone axis; (b, e) the DF images recorded using $\omega$ reflection, marked with a white circle in (a) and (c), respectively; (c, f) the DF images recorded using alpha reflection, marked with a black circle in (a) and (c), respectively.

indicated that $\omega$ was destabilized with increasing $|\Delta|$ [10] [11]. The coarse and fine microstructures respectively had a $|\Delta|$ value of 0.11 and 0.13 , suggesting that $\omega$ phase in the former was more stable than the latter.

TEM studies were carried out the two materials, as shown in Figure 4. Figure 4(a) was a DF image taken from the coarse microstructure, using one of the $\alpha_{2}$ phase reflections (Figure $4(\mathrm{~b})$ ). The nanometer-scale $\alpha_{2}$ precipitates were found along the $\alpha / \beta$ interface (Figure 4(a)). The selected area electron diffraction pattern (SADP) from the fine microstructure showed both fundamental reflections resulting from the $\alpha$ phase and quite faint reflections at the $1 / 2\{10-10\}_{\alpha}$, which was a direct evidence for the presence of $\alpha_{2}$ precipitates. Faint reflections suggested that the fine microstructure has $\alpha_{2}$ phase with much smaller size and lower volume fraction compared to the coarse microstructure.

\subsection{Mechanical Properties}

The mechanical properties of TC21 titanium alloy with the coarse and the fine microstructures heat treated at $900^{\circ} \mathrm{C} / 1 \mathrm{~h}+550^{\circ} \mathrm{C} / 4 \mathrm{~h}$ were displayed in Table 1 . The fine microstructure showed excellent comprehensive properties. It was observed its strength is better than that of the coarse microstructure. Meanwhile, the difference between the two microstructures was considerable, approximately $60 \mathrm{Mpa}$ in ultimate tensile stress and $50 \mathrm{MPa}$ in yield stress. The elongation of the fine and coarse microstructures was $8.5 \%$ and $7 \%$, respectively, which showed a significant difference of $21.4 \%$. It was noticeable that the fracture toughness of the fine microstructure was approximately $19 \mathrm{MPa} \cdot \mathrm{m}^{1 / 2}$ higher than that of the 

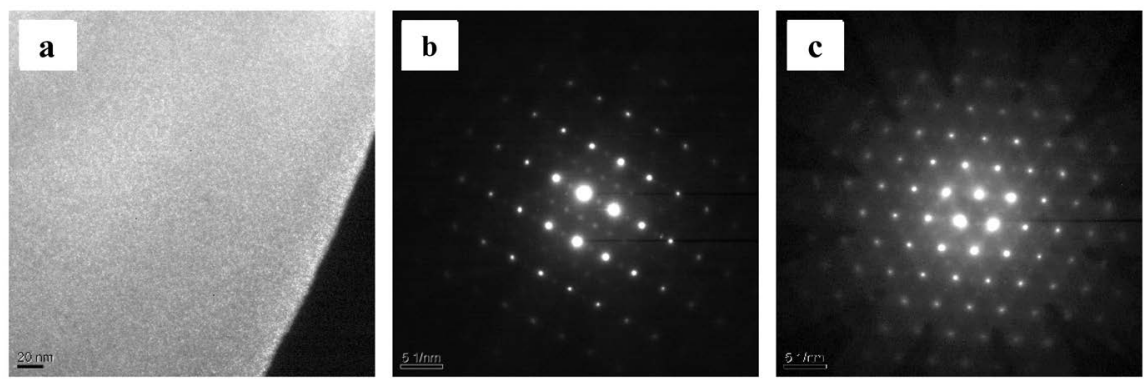

Figure 4. DF images (a) and the SADPs (b) taken from the coarse microstructure TC21 titanium alloy heat treated at $900^{\circ} \mathrm{C} / 1 \mathrm{~h}+550^{\circ} \mathrm{C} / 4 \mathrm{~h}$; The SADPs (c) taken from the fine microstructure TC2 1 titanium alloy heat treated at $900^{\circ} \mathrm{C} / 1 \mathrm{~h}+550^{\circ} \mathrm{C} / 4 \mathrm{~h}$.

Table 1. Room temperature mechanical properties of TC21 titanium alloys with fine and coarse microstructures heat-treated at $900^{\circ} \mathrm{C} / 1 \mathrm{~h}+550^{\circ} \mathrm{C} / 4 \mathrm{~h}$

\begin{tabular}{cccccc}
\hline Material & $\mathrm{UTS} / \mathrm{MPa}$ & $\mathrm{YS} / \mathrm{MPa}$ & $\mathrm{EL} / \%$ & $\mathrm{RA} / \%$ & $\mathrm{~K}_{\mathrm{IC}} / \mathrm{MPa} \cdot \mathrm{m}^{1 / 2}$ \\
\hline Coarse microstructure & 1220 & 1120 & 7 & 25 & 36 \\
Fine microstructure & 1280 & 1170 & 8.5 & 25.5 & 55 \\
\hline
\end{tabular}

coarse microstructure. Those results indicated that the fine microstructure material had excellent comprehensive properties.

\subsection{Crack Growth Behaviour}

Crack path observations in additional CT-materials, which were TC21 titanium alloy with the coarse and fine microstructures heat treated at $900^{\circ} \mathrm{C} / 1 \mathrm{~h}+$ $550^{\circ} \mathrm{C} / 4 \mathrm{~h}$, were illustrated in Figure 5. Microcracks along the interphase and the boundary of $\beta$-phase grains were clearly seen in the white ellipses of Figure 5, suggesting that the microcracks might nucleate at the interphase. Meanwhile, some contacts were observed in the two microstructures, as were marked by white arrows in Figure 5. Some bridging elements were only found in the fine microstructure, as are marked by the black arrows of Figure 5(b). In addition, some microcracks near the main crack were also found in the fine microstructure, marked by the black ellipses of Figure 5(b). They merged into the main crack when microcracks coarsened to about $55 \mu \mathrm{m}$ (Figure 5), which indicated that smaller microcracks tended to form bridging elements. Microcracks in the fine microstructure were smaller than those in the coarse microstructure (Figure 5). Therefore, more bridging elements inducing the stress shilding will generate in the fine microstrucure, which is beneficial to the blunting of crack tips, namely, to reduce the crack growth rate [11].

\section{Discussions}

\subsection{Effect of Initial Microstructure on Phase Precipitations}

According to Sections 2 and 3.1, it was obvious that during heat treatment, $\alpha$ grains in the coarse microstructure grew slightly while coarsened greatly in the fine microstructure. This phenomenon may be explained by the typical Ostwald 

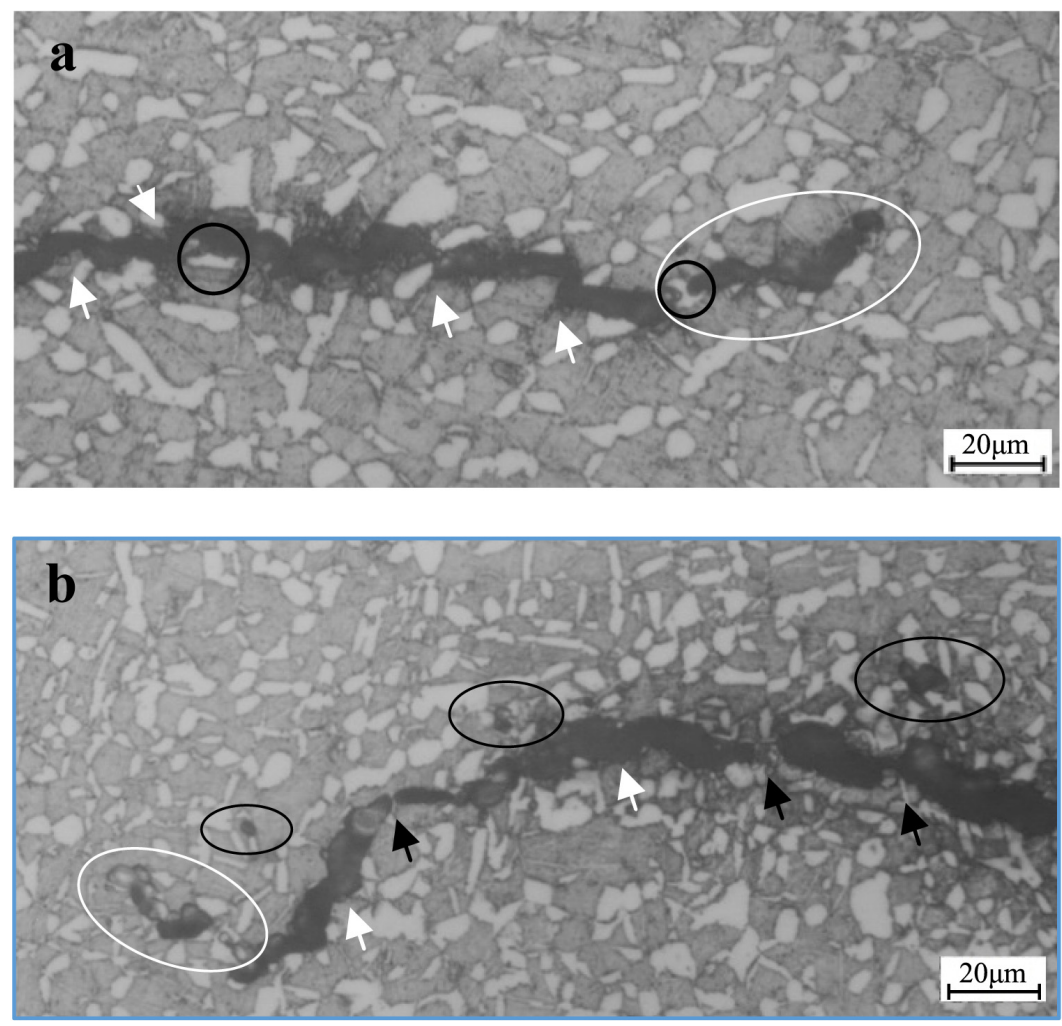

Figure 5. Crack paths in heat-treated TC21 titanium alloys with (a) coarse and (b) fine microstructures.

ripening processes [12]. The process consists of two phases. In the first phase, the cube of the average grain radius is proportional to time. In the second phase, the average grain radius remains self-similar when scaled by a certain grain size. The coarsening of the coarse microstructure after heat treatment may follow the first phase of Ostwald ripening processes [12]. However, the coarsening behavior of the fine microstructure can be described by the second phase. The precipitations in tianium alloys are influenced by many factors such as element contents, processing history, and heat treatment, however, essentially result from the compositional fluctuation [13] [14] [15] [16]. With increasing Al content, the size and the volume fraction of $\alpha_{2}$ precipitation increase [13]. The Al contents of the $\alpha$ in the coarse and the fine microstructures were 7.46 and $5.76 \mathrm{wt} \%$, respectively, as shown in Table 2. It is easy to understand that, at the same heat-treatment condition, the $\alpha_{2}$ precipitation of the fine microstructure was fewer and smaller than that of coarse microstructure. Moreover, low and high $\mathrm{Al}$ contents in the $\beta$ field were found in the coarse and fine microstructures, respectively (Table 2). Higher addition content of $\mathrm{Al}$ results in the formation of alpha phase more effectively than $\omega$ phase [10]. Therefore, during the heat treatment, the thicker alpha lamellae and more instable $\omega$ phase are found in the fine microstructure.

\subsection{Effect of Initial Microstructure on Mechanical Properties}

The high combination properties of the heat-treated fine microstructure are very 
Table 2. EDS data of different phases in TC21 titanium alloys with coarse and fine microstructures (wt\%).

\begin{tabular}{ccccccccc}
\hline material & phase & $\mathrm{Al}$ & $\mathrm{Sn}$ & $\mathrm{Zr}$ & $\mathrm{Cr}$ & $\mathrm{Mo}$ & $\mathrm{Nb}$ & $\mathrm{Si}$ \\
\hline \multirow{2}{*}{ Coarse microstructure } & $\beta$ & 3.24 & 2.09 & 2.31 & 2.56 & 4.52 & 2.58 & 0.14 \\
& Equiaxed $\alpha$ & 7.46 & 1.98 & 2.01 & 0.61 & 0.86 & 1.34 & 0.06 \\
Fine microstructure & $\beta$ & 5.88 & 2.49 & 2.28 & 2.04 & 3.26 & 2.49 & 0.09 \\
& Equiaxed $\alpha$ & 5.76 & 2.09 & 1.9 & 1.04 & 1.92 & 1.55 & 0.1 \\
\hline
\end{tabular}

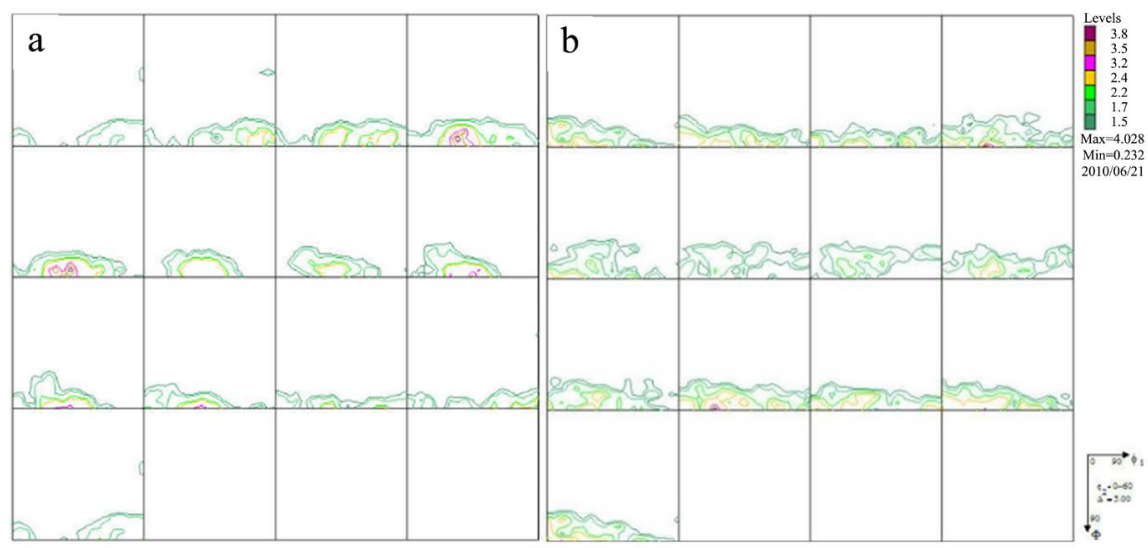

Figure 6. ODF sections of $\alpha$ textures from heat-treated TC21 titanium alloys with (a) coarse and (b) fine microstructures.

interesting. First, high strength can be attributed to the fine equiaxed $\alpha$ microstructure according to Hall-Petch equation. Another factor that may contribute to the high ductility is $\left\langle\mathrm{uvt} 0{ }_{a} / / \mathrm{RD}\right.$ fibrous texture (Figure 6), namely, the orientation of the tensile axis (RD) perpendicular to the $[0001]_{\alpha}$. The prismatic gliding $\left(\{1-100\}_{\alpha}<11-20>_{\alpha}\right.$ ) operates easily during the tensile test, which may result in an increase in ductility [7]. Under the same heat-treatment conditions, the fine microstructure also shows higher fracture toughness, compared with the coarse microstructure. The reasons are as following: First, fine microstructure is beneficial to generate more and smaller microcracks near the crack tip and the main crack, which can reduce stress concentration in this field, namely, to lead to higher energy absorption during deformation; Second, the increased amount of $\alpha_{2}$ precipitate may promote the basal slip ((0001) [11 - 20]), which can reduce the fracture of the tested samples [17].

\section{Conclusions}

1) The initial microstructure of TC21 titanium affects the microstructure evolution and phase precipitates during heat treatment. After heat treatment, the fine microstructure forms a duplex microstructure with small $\alpha$ grains and thick second alpha lamellae while the coarse microstructure develops a duplex microstructure with large $\alpha$ grain and thin second $\alpha$ lamellae. Moreover, more instable $\omega$ and $\alpha_{2}$ precipitates of much smaller size and lower volume fraction are observed in the heat-treated fine microstructure. 
2) Crack growth behavior of TC21 titanium greatly depends on the initial microstructure under the same heat treatment condition. The fine microstructure exhibits lower crack growth resistance than the coarse microstructure.

3) During heat treatment, the initial microstructure of TC21 titanium has a great effect on mechanical properties. The compresensive property of fine microstructure is superior to that of the coarse microstructure.

\section{Acknowledgements}

The present work is supported by National Natural Science Foundation of China (No. 51301010) and Scientific Research Foundation for Advanced Talents (TZXY2017QDJJ012).

\section{Conflicts of Interest}

The authors declare no conflicts of interest regarding the publication of this paper.

\section{References}

[1] Wang, L.R., Ma, C.L., Zhao, Y.Q. and Zhou, L. (2016) Effect of $\beta$ Heat Treatment on Phase Transformations of TC21 during Rolling. Materials Science and Technology, 32, 635-640. https://doi.org/10.1179/1743284715Y.0000000055

[2] Wang, Y.S., Xiu, S.C., Zhang, S.N. and Jiang, C.Y. (2020) Effect of Grinding Parameters on Microstructure Evolution of TC21 Titanium Alloy with Bimodal Starting Microstructure. Journal of Alloys and Compounds, 831, 1-10. https://doi.org/10.1016/j.jallcom.2020.154882

[3] Shi, Z.F., Guo, H.Z., Han, J.Y. and Yao, Z.K. (2014) Microstructure and Mechanical Properties of TC21 Titanium Alloy after Heat Treatment. Transactions of Nonferrous Metals Society of China, 23, 2882-2889. https://doi.org/10.1016/S1003-6326(13)62810-1

[4] Elshaer, R.N. and Ibrahim, K.M. (2020) Effect of Cold Deformation and Heat Treatment on Microstructure and Mechanical Properties of TC21 Ti Alloy. Transactions of Nonferrous Metals Society of China, 30, 1290-1299. https://doi.org/10.1016/S1003-6326(20)65296-7

[5] Zherebtsov, S., Mazur, A., Salishchev, G. and Lojkowski, W. (2008) Effect of Hydrostatic Extrusion at $600-700{ }^{\circ} \mathrm{C}$ on the Structure and Properties of Ti-6Al-4V Alloy. Materials Science and Engineering, 485A, 39-45. https://doi.org/10.1016/j.msea.2007.08.081

[6] Zherebtsov, S., Urzinova, M.M. and Salishchev, G. (2011) Spheroidization of the Lamellar Microstructure in Ti-6Al-4V Alloy during Warm Deformation and Annealing. Acta Materialia, 59, 4128-4150. https://doi.org/10.1016/j.actamat.2011.03.037

[7] Stolyarov, V.V., Zhu, Y.T., Alexandeov, I.V., Lowe, T.C. and Valiev, R.Z. (2003) Grain Refinement and Properties of Pure Ti Processed by Warm ECAP and Cold Rolling. Materials Science and Engineering, 343A, 43-50. https://doi.org/10.1016/S0921-5093(02)00366-0

[8] Zherebtsov, S.V., Salishchev, G.A., Galeyev, R.M., Valiakhmetov, O.R., Mironov, S.Y. and Semiatin, S.L. (2004) Production of Submicrocrystalline Structure in 
Large-Scale Ti-6Al-4V Billet by Warm Severe Deformation Processing. Scripta Materialia, 51, 1147-1151. https://doi.org/10.1016/j.scriptamat.2004.08.018

[9] Lonardelli, I., Gey, N., Wenk, H.-R., Humbert, M., Vogel, S.C. and Lutterotti, L. (2007) In Situ Observation of Texture Evolution during $\alpha \rightarrow \beta$ and $\beta \rightarrow \alpha$ Phase Transformation in Titanium Alloys Investigated by Neutron Diffraction. Acta Materialia, 55, 5718-5727. https://doi.org/10.1016/j.actamat.2007.06.017

[10] Shao, G. and Tsakiroporlos, P. (2018) On the $\omega$ Phase Formation in Cr-Al and Ti-Al-Cr Alloys. Acta Materialia, 48, 3671-3685. https://doi.org/10.1016/S1359-6454(00)00168-3

[11] Gnanamoorthy, R., Mutoh, Y. and Mizuhara, Y. (1996) Fatigue Crack Growth Behavior of Equiaxed, Duplex and Lamellar Microstructure $\gamma$-Base Titanium Aluminides. Intermetallica, 4, 525-532. https://doi.org/10.1016/0966-9795(96)00028-3

[12] Baldan, A. (2002) Progress in Ostwald Ripening Theories and Their Applications to Nick-Base Superalloys. Journal of Materials Science, 37, 2171-2202. https://doi.org/10.1023/A:1015388912729

[13] Huang, A.J., Li, G.P., Hao, Y.L. and Yang, R. (2003) Acicular $\alpha_{2}$ Precipitation Induced by Capillarity at $\alpha / \beta$ Phase Boundaries in Ti-14Al-2Zr-2Sn-3Sn-3Mo-0.5Si Titanium Alloy. Acta Materialia, 51, 4939-4952. https://doi.org/10.1016/S1359-6454(03)00352-5

[14] Zhang, X.D., Wiezorek, J.M.K., Baeslack, W.A. III, Evans, D.J. and Fraser, H.L. (1998) Precipitation of Ordered $\alpha_{2}$ Phase in Ti-6-22-22 Alloy. Acta Materialia, 46, 4485-4495. https://doi.org/10.1016/S1359-6454(98)00158-X

[15] Nag, S., Zheng, Y., Williams, R., Devaraj, A. and Boyne, A. (2012) Non-Classical Homogenous Precipitation Mediated by Composition Fluctuations in Titanium Alloys. Acta Materialia, 60, 6247-6256. https://doi.org/10.1016/j.actamat.2012.07.033

[16] Zhang, X.D., Wiezorek, J.M.K., Baeslack, W.A. III, Evans, D.J. and Fraser, H.L. (1999) On the Stability of $\omega$ Phase in Ti-6-22-22S and Ti-6-4 Alloys. Scipta Materialia, 41, 659-665. https://doi.org/10.1016/S1359-6462(99)00111-6

[17] Zeng, W.D. and Zhou, Y.G. (2000) The Influence of Microstructure on Dwell Sensitive Fatigue in Ti-6.5Al-3.5Mo-1.5Zr-0.3Si Alloy. Materials Science and Engineering, 290A, 33-38. https://doi.org/10.1016/S0921-5093(00)00941-2 